\title{
ESTIMATION OF RANDOM FRICTION FORCES ON THE MICROBEARING COOPERATING SURFACES
}

\author{
Krzysztof Wierzcholski \\ Technical University of Koszalin, Faculty of Technology and Education \\ Śniadeckich Street 2, 75-453 Koszalin, Poland \\ tel.: +48943478344, fax: +48943426753 \\ e-mail: krzysztof.wierzcholski@wp.pl
}

Andrzej Miszczak

Gdynia Maritime University, Faculty of Marine Engineering

Morska Street 81-87, 81-225 Gdynia, Poland

tel.: +48585586348, fax: +48585586399

e-mail:a.miszczak@wm.umg.edu.pl

\begin{abstract}
Presented paper concerns a new mathematical form of stochastic theory of hydrodynamic friction forces occurring on the real cooperating surfaces in computer micro bearing fan and computer microbearing in hard disc driver HDD. This paper presents particularly a new-review of stochastic analytical considerations realized by the authors for friction forces estimation during hydrodynamic lubrication performed on the ground of the measurements of the gap height between two roughness surfaces. After numerous experimental measurements directly follows that the random unsymmetrical increments and decrements of the gap height of computer microbearings have important influence on the load carrying capacities and finally on the friction forces and wear of cooperating surfaces. The main topic demonstrates the influence of the variations of expectancy values and standard deviation of the computer microbearing gap height on the friction forces occurring in the HDD and microbearing fan. Moreover, it is observed the evident connection between the apparent dynamic viscosity and the features of the microbearing superficial surface. Hence after abovementioned remarks follows the corollary that the influence of the microbearing gap height stochastic variations connected with the surface roughness tend moreover indirect from the apparent viscosity into the friction forces variations. The synthetic, complex elaboration of obtained results indicates finally the influence of the random roughness in micro and nano level of microbearing surfaces on the friction forces distribution. A new results contained in this paper are obtained taking into account $3 D$ variations of dynamic viscosity of the non-Newtonian lubricant, particularly variations crosswise the film thickness and influences of surface superficial layer features on the lubricant apparent viscosity.
\end{abstract}

Keywords: microbearings, computer fan, hard disc driver bearings, hydrodynamic lubrication, analytical stochastic principles, analytical solutions, apparent viscosity depended on the gap height variations

\section{Introduction}

In this paper are presented the determinations and estimations of the friction forces occurring in various kinds of microbearings. This paper considers microbearing among other in computer fan and computer HDD. Radial clearance (RC) of the considered cylindrical microbearing is formed by outer cylindrical surface of the journal and the inner cylindrical surface of the sleeve. The microbearings can have the following parameters:

- RC $2.8 \mu \mathrm{m}$, radius of journal - $2000 \mathrm{~mm}, 15000 \mathrm{RPM}$,

- RC $3.15 \mu \mathrm{m}$, radius of journal - $1995 \mathrm{~mm}, 5000-10000 \mathrm{RPM}$,

- RC $5 \mu \mathrm{m}$ and $15 \mu \mathrm{m}$, radius of journal $-2500 \mathrm{~mm}, 20000 \mathrm{RPM}$.

The results of the latest numerous studies concerning microbearings exploitation problems, carried out by means of an atomic force microscope (AFM), have demonstrated that the gap height 
between co-operating surfaces and its superficial layer, fairly significantly controls the course of hydrodynamic lubrication of surfaces flown-around by the non-Newtonian lubricants [1-10].

During the lubricant flow in the microbearing gap, the random roughness of the movable superficial layer always changes in stochastically sense the gap height [4-6]. On the ground of latest, numerous measurements performed by the AFM follows, that the total gap height $\varepsilon_{\mathrm{T}}$ has random changes manifested by the increments or decrements in comparison to the height of the nominal mean value [10-17]. Mentioned changes $\delta$ can be caused by the random micro vibration, by the non-continuous random loading of the microbearing, stochastic changes of roughness geometry [7]. Random changes of the microbearing gap height have direct and indirect influences on the stochastic friction forces. The direct influences are visible in analytical solutions presenting the fiction forces depended on the gap height. The indirect influences of the random gap height variations on the friction forces are provoked by the stochastic changes of the lubricant dynamic viscosity. The random increments (decrements) of the ultra-thin gap height imply decreases (increases) of average velocity values of the non-Newtonian lubricant i.e. the share rate decreases (increases) respectively. Hence, for non-Newtonian lubricant flow follows that the viscosity of the mentioned lubricant increases (decreases). Finally, the friction forces depend strongly on the lubricant dynamic viscosity.

The to-date is numerous experimental studies on the effects, exerted by the load or the features of the microbearing cooperating surfaces and lubricant dynamic viscosity on the course of hydrodynamic surface lubrication process in general were biased by the chemical character, both in experimental aspects $[3,6,11]$. None of those studies has till now not been subject of any tribological verification, based on analytical-numerical hydrodynamics. This fact inspired the author to undertake studies of the influence of the features of cooperating surfaces on the random lubricant viscosity and random friction forces determination and estimation in the scope of tribology and mechanics. The aims of this paper are direct and indirect influences of random gap height variations on the lubricant viscosity and stochastic value of friction forces occurring in the microbearing cooperating surfaces.

\section{Random gap height with probability density function and standard deviation}

The calculations and description of the microbearing construction are performed in cylindrical coordinates $(\varphi, \mathrm{r}, \mathrm{z})$, where $\varphi$ - circumferential direction, $\mathrm{r}$ - radial direction, $\mathrm{z}$ - meridian longitudinal direction in the microbearing length. The geometry of the microbearing is presented in Fig. 1.

Lubrication region $\Omega$ is defined by the following inequalities: $0<\varphi<\pi$; $-\mathrm{b}<\mathrm{z}<+\mathrm{b}$, b - halflength of the microbearing journal. Gap height $\varepsilon_{\mathrm{T}}$ for eccentricity $\lambda$ between two microbearing cooperating nominal smooth cylindrical surfaces and deformed by the stochastic variations we can show in following dimensional form $[6,7]$ :

$$
\begin{gathered}
\varepsilon_{\mathrm{T}}\left(\varphi, \mathrm{z}_{1}, \delta_{1}\right)=\varepsilon_{0} \varepsilon_{\mathrm{T} 1}\left(\varphi, \mathrm{z}_{1}, \delta_{1}\right)=\varepsilon_{0} \varepsilon_{\mathrm{T} 1}\left(\varphi, \mathrm{z}_{1}\right) \cdot\left[1+\delta_{1}\left(\varphi, \mathrm{z}_{1}\right)\right], \\
\varepsilon_{\mathrm{T}}\left(\delta_{1}=0\right)=\varepsilon_{0} \varepsilon_{\mathrm{T} 1}\left(\varphi, \mathrm{z}_{1}\right)=\varepsilon_{0}\left[1+\lambda \cdot \cos (\varphi)+\mathrm{a}_{\gamma} \mathrm{z}_{1} \cos (\varphi)\right], \\
\mathrm{a}_{\gamma}=\frac{\mathrm{L}_{1}}{\psi} \tan (\gamma), \mathrm{z}_{1}=\mathrm{z} / \mathrm{b}, \mathrm{L}_{1}=\mathrm{b} / \mathrm{R}, \psi=\frac{\varepsilon_{0}}{\mathrm{R}},
\end{gathered}
$$

where: $\mathrm{a}_{1}$ - coefficient of misalignment, $\mathrm{z}_{1}$ - dimensionless longitudinal coordinate, $\lambda$-relative eccentricity $\delta_{1}$-dimensionless random variable of corrections, $\gamma$-angle between the axes, $\varepsilon_{0}-$ radial clearance, $\mathrm{L}_{1}$ - dimensionless bearing length.

The expectancy value of the arbitrary correction parameter $\left(^{*}\right)$ and of the total gap, height is defined by the following expressions [7]: 


$$
\begin{gathered}
\mathrm{EX}(*)=\int_{-\infty}^{+\infty}(*) \times \mathrm{f}(*) \mathrm{d}(*), \\
\operatorname{EX}\left(\varepsilon_{\mathrm{T} 1}\right)=\operatorname{EX}\left[\varepsilon_{\mathrm{T} 1 \mathrm{~s}}\left(1+\delta_{1}\right)\right]=\varepsilon_{\mathrm{T} 1 \mathrm{~s}}\left[1+\mathrm{EX}\left(\delta_{1}\right)\right]=\varepsilon_{\mathrm{T} 1 \mathrm{~s}}\left[1+\int_{-\infty}^{+\infty}\left(\delta_{1}\right) \times \mathrm{f}\left(\delta_{1}\right) \mathrm{d} \delta_{1}\right] .
\end{gathered}
$$

We denote EX - expectancy operator, $\left(^{*}\right)$ - considered dimensionless correction parameter $\delta_{1}$, $\mathrm{f}$ - probability density function obtained from the measurements. Function $\mathrm{f}$ depends on the dimensionless correction parameter $\delta_{1}=(*)$. Standard deviation $\sigma$, for correction parameter has the following form [7]:

$$
\sigma \equiv \sqrt{\mathrm{EX}(*)^{2}-\mathrm{EX}^{2}(*)}
$$
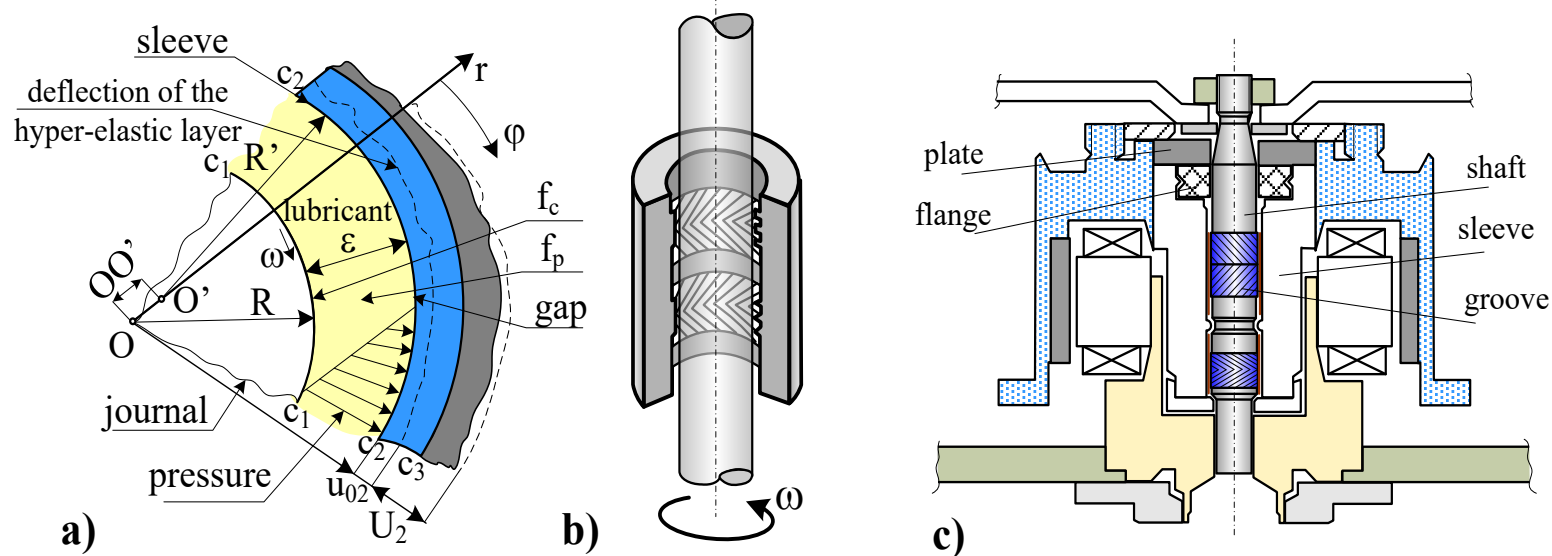

Fig. 1. Microbearing: a) geometry of the gap 5-15 $\mathrm{mm}$, b) microbearing shaft $3 \mathrm{~mm}$, c) high speed HDD (15000 rpm) with the journal

In performed measurements $[15,16]$ the values of probability density function $f$ are the probabilities assigned for positive or negative gap height correction values $\delta$ due to random roughness and its asperities of in individual point on the microbearing cooperating surfaces. The measurements of the gap height corrections $\delta$ due to the random roughness are performed on the sample $(0.2 \mathrm{~mm} \times 0.2 \mathrm{~mm})$ of the microbearing surface using mechanical sensor $[7,11,18]$. Obtained results are presented in Fig. 2.

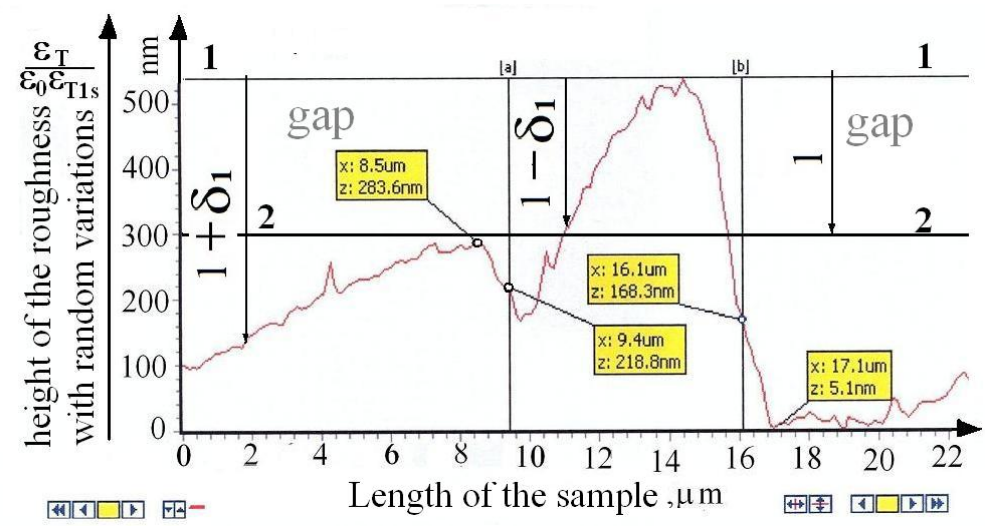

Fig. 2. Random changes of joint gap height $\varepsilon_{T}$ due to random roughness: a) measurement of rough values on the sample $(0.2 \mathrm{~mm} \times 0.2 \mathrm{~mm})$ along the ten percent sample length from 0 to $20 \mu \mathrm{m}$, b) asperities of the sleeve surface restricted the gap along the 1-1 cross-section; 1 - middle axis of the gap height between two smooth cooperating surfaces, 2 - throw of the smooth sleeve surface restricted the gap without random roughness variations 


\section{Governing equations in cylindrical coordinates}

The lubrication problem is described by the following equations: equilibrium of momentum equations, continuity equation, energy equation. We take into account the following random expected values for: hydrodynamic pressure $\operatorname{EX}[p(\varphi, z)]$, temperature $\operatorname{EX}[\mathrm{T}(\varphi, r, z)]$, fluid velocity components $\operatorname{EX}\left[\mathrm{v}_{\mathrm{i}}(\varphi, \mathrm{r}, \mathrm{z})\right]$ for $\mathrm{i}=\varphi, \mathrm{r}, \mathrm{z}$; random dynamic viscosity of the lubricant $\operatorname{EX}\left[\eta_{\mathrm{T}}(\varphi, \mathrm{r}, \mathrm{z})\right]$, and random microbearing gap height $\operatorname{EX}\left[\varepsilon_{\mathrm{T}}(\varphi, \mathrm{z})\right]$. Here are neglected lubricant density variations i.e. incompressible liquid is considered. The influences of electrostatic field on the viscosity of the lubricant are taken into account [14]. We apply the boundary layer simplifications in abovementioned system of hydrodynamic equations i.e. we neglect the terms of order of radial clearance equal to value $10^{-4}$. After calculations and term ordering, we obtain following system of hydrodynamic lubrication equation in stochastic form [14]:

$$
\begin{gathered}
0=-\frac{1}{\mathrm{R}} \frac{\partial \mathrm{EX}(\mathrm{p})}{\partial \varphi}+\frac{\partial}{\partial \mathrm{r}}\left\{\operatorname{EX}\left[\eta_{\mathrm{T}}(\varphi, \mathrm{r}, \mathrm{z})\right] \frac{\partial \mathrm{EX}\left(\mathrm{v}_{\varphi}\right)}{\partial \mathrm{r}}\right\}, \\
0=\frac{\partial \mathrm{EX}(\mathrm{p})}{\partial \mathrm{r}}, \\
0=-\frac{\partial \mathrm{EX}(\mathrm{p})}{\partial \mathrm{z}}+\frac{\partial}{\partial \mathrm{r}}\left\{\operatorname{EX}\left[\eta_{\mathrm{T}}(\varphi, \mathrm{r}, \mathrm{z})\right] \frac{\partial \mathrm{EX}\left(\mathrm{v}_{\mathrm{z}}\right)}{\partial \mathrm{r}}\right\}, \\
\frac{\partial}{\mathrm{R} \partial \varphi}\left[\operatorname{EX}\left(\mathrm{v}_{\varphi}\right)\right]+\frac{\partial}{\partial \mathrm{r}}\left[\operatorname{EX}\left(\mathrm{v}_{\mathrm{r}}\right)\right]+\frac{\partial}{\partial \mathrm{z}}\left[\operatorname{EX}\left(\mathrm{v}_{\mathrm{z}}\right)\right]=0, \\
\frac{\partial}{\partial \mathrm{r}}\left\{\kappa \frac{\partial}{\partial \mathrm{r}}[\operatorname{EX}(\mathrm{T})]\right\}+\operatorname{EX}\left[\eta_{\mathrm{T}}(\varphi, \mathrm{r}, \mathrm{z})\right]\left[\left(\frac{\partial}{\partial \mathrm{r}}\left[\operatorname{EX}\left(\mathrm{v}_{\varphi}\right)\right]\right)^{2}+\left(\frac{\partial}{\partial \mathrm{r}}\left[\operatorname{EX}\left(\mathrm{v}_{\mathrm{z}}\right)\right]\right)^{2}\right]=0,
\end{gathered}
$$

where expected value of apparent viscosity $\eta_{T}$ in [Pas] has the following form:

$$
\operatorname{EX}\left[\eta_{\mathrm{T}}(\varphi, r, z)\right]=\operatorname{EX}\left[\eta_{\mathrm{T}}(\theta, \mathrm{T}, \mathrm{p})\right],
$$

for $0 \leq \mathrm{r} \leq \operatorname{EX}\left[\varepsilon_{\mathrm{T}}(\varphi, \mathrm{z})\right], 0<\varphi<\pi,-\mathrm{b}<\mathrm{z}<+\mathrm{b}$. We denote: $\operatorname{EX}(\mathrm{T})$ in $[\mathrm{K}]-$ expected value of random temperature variations in lubricant, $\kappa$ in $[\mathrm{W} / \mathrm{mK}]$ - thermal conductivity coefficient for lubricant, $\rho$ in $\left[\mathrm{kg} / \mathrm{m}^{3}\right]$ - lubricant density, $\theta$ in $1 / \mathrm{s}-$ shear rate during the lubricant flow.

The system of partial differential equations (4)-(8) determines following expected values of unknown random functions, namely: three components of oil velocity $\operatorname{EX}\left[\mathrm{v}_{\mathrm{i}}(\varphi, \mathrm{r}, \mathrm{z})\right]$ in $[\mathrm{m} / \mathrm{s}]$ for $\mathrm{i}=\varphi, \mathrm{r}, \mathrm{z}$; hydrodynamic pressure $\operatorname{EX}[\mathrm{p}(\varphi, \mathrm{z})]$ in $[\mathrm{Pa}]$, temperature $\operatorname{EX}[\mathrm{T}(\varphi, \mathrm{r}, \mathrm{z})]$ in $[\mathrm{K}]$. Apparent viscosity expression (9) had been obtained from experimental measurements.

\section{Integrals for random hydrodynamic lubrication}

Random variable gap height $\varepsilon_{\mathrm{T}}$ filled up with lubricant (without cavitation) is restricted by the motionless sleeve and by the movable journal with angular velocity $\omega$. Therefore, we impose following boundary conditions on the expected values of lubricant velocity components [14]:

$$
\begin{gathered}
\mathrm{EX}\left(\mathrm{v}_{\varphi}\right)=\omega \mathrm{R} \text { for } \mathrm{r}=0, \mathrm{EX}\left(\mathrm{v}_{\varphi}\right)=0 \text { for } \mathrm{r}=\mathrm{EX}\left(\varepsilon_{\mathrm{T}}\right), \mathrm{EX}\left(\mathrm{v}_{\mathrm{z}}\right)=0 \text { for } \mathrm{r}=0, \mathrm{EX}\left(\mathrm{v}_{\mathrm{z}}\right)=0 \text { for } \mathrm{r}=\mathrm{EX}\left(\varepsilon_{\mathrm{T}}\right), \\
\qquad \mathrm{EX}\left(\mathrm{v}_{\mathrm{r}}\right)=0 \text { for } \mathrm{r}=0, \text { and } \mathrm{EX}\left(\mathrm{v}_{\mathrm{r}}\right)=0 \text { for } \mathrm{r}=\mathrm{EX}\left(\varepsilon_{\mathrm{T}}\right) .
\end{gathered}
$$

Determination of the expected value of temperature $\operatorname{EX}[\mathrm{T}(\varphi, \mathrm{r}, \mathrm{z})]$ from the second order partial differential equation (8) requires two boundary conditions. We assume characteristic environmental 
temperature $T_{0}$, the constant value of temperature $f_{c}$ on the movable journal surface, the unknown temperature $f_{p}(\varphi, z)$ on the motionless sleeve surface. Hence, we have:

$$
\operatorname{EX}[T(\varphi, r, z)]=T_{0}+f_{c} \text { for } r=0 \text {, and } \operatorname{EX}[T(\varphi, r, z)]=T_{0}+f_{p}(\varphi, z) \text { for } r=\operatorname{EX}\left(\varepsilon_{T}\right) \text {. }
$$

To determine the unknown function of the temperature $f_{p}(\varphi, z)$ in $[K]$ on the sleeve surface, we take into account the condition of heat flux flow density $\mathrm{q}_{\mathrm{c}}$ in $\left[\mathrm{W} / \mathrm{m}^{2}\right]$ from the journal surface through the lubricant onto the sleeve surface. Such condition has the following form:

$$
\kappa \frac{\partial \mathrm{EX}(\mathrm{T})}{\partial \mathrm{r}}=-\mathrm{q}_{\mathrm{c}} \text { for } \mathrm{r}=0 .
$$

Hence after calculations and term ordering we obtain the following equation determining the expected value of the hydrodynamic pressure $\operatorname{EX}[\mathrm{p}(\varphi, \mathrm{z})]$ :

$$
\frac{1}{\mathrm{R}^{2}} \frac{\partial}{\partial \varphi}\left[\left(\frac{\partial \mathrm{EX}(\mathrm{p})}{\partial \varphi}\right)\left(\int_{0}^{\mathrm{EX}\left(\varepsilon_{\mathrm{T}}\right)} \mathrm{A}_{\eta} \mathrm{dr}\right)\right]+\frac{\partial}{\partial \mathrm{z}}\left[\left(\frac{\partial \mathrm{EX}(\mathrm{p})}{\partial \mathrm{z}}\right)\left(\int_{0}^{\mathrm{EX}\left(\varepsilon_{\mathrm{T}}\right)} \mathrm{A}_{\eta} \mathrm{dr}\right)\right]=\omega \frac{\partial}{\partial \varphi}\left[\left(\int_{0}^{\mathrm{EX}\left(\varepsilon_{\mathrm{T}}\right)} \mathrm{A}_{\eta} \mathrm{dr}\right)-\operatorname{EX}\left(\varepsilon_{\mathrm{T}}\right)\right],
$$

where $0 \leq \mathrm{r} \leq \varepsilon_{\mathrm{T}}(\varphi, \mathrm{z}), 0<\varphi<\pi ;-\mathrm{b}<\mathrm{z}<\mathrm{b}$, and for lubricant viscosity $\eta_{\mathrm{T}}=\eta_{\mathrm{T}}(\varphi, r, \mathrm{z})$ we have:

$$
A_{s}(\varphi, r, z) \equiv \frac{\int_{0}^{r} \frac{d r}{\operatorname{EX}\left(\eta_{T}\right)}}{\int_{0}^{\operatorname{EX}\left(\varepsilon_{\mathrm{T}}\right)} \frac{d r}{\operatorname{EX}\left(\eta_{\mathrm{T}}\right)}}, \quad A_{\eta}(\varphi, r, z) \equiv \int_{0}^{\mathrm{r}} \frac{\mathrm{rdr}}{\operatorname{EX}\left(\eta_{\mathrm{T}}\right)}-\mathrm{A}_{\mathrm{s}}(\varphi, r, z) \int_{0}^{\operatorname{EX}\left(\varepsilon_{\mathrm{T}}\right)} \frac{\mathrm{rdr}}{\operatorname{EX}\left(\eta_{\mathrm{T}}\right)}
$$

The components of expected random values of friction forces $F_{R \varphi}$ in $[N], F_{R z}$ in $[N]$ in cylindrical directions $\varphi, z$ occurring in slide microbearing have the following forms:

$$
\operatorname{EX}\left(\mathrm{F}_{\mathrm{R} \varphi}\right)=\iint_{\Omega}\left(\operatorname{EX}\left(\eta_{\mathrm{T}}\right) \frac{\partial \mathrm{EX}\left(\mathrm{v}_{\varphi}\right)}{\partial \mathrm{r}}\right)_{\mathrm{r}=\mathrm{EX}\left(\varepsilon_{\mathrm{T}}\right)} \operatorname{Rd} \varphi \mathrm{dz}, \operatorname{EX}\left(\mathrm{F}_{\mathrm{Rz}}\right)=\iint_{\Omega}\left(\operatorname{EX}\left(\eta_{\mathrm{T}}\right) \frac{\partial \mathrm{EX}\left(\mathrm{v}_{\mathrm{z}}\right)}{\partial \mathrm{r}}\right)_{\mathrm{r}=\operatorname{EX}\left(\varepsilon_{\mathrm{T}}\right)} \operatorname{Rd} \varphi \mathrm{dz},
$$

where $\operatorname{EX}\left(\varepsilon_{\mathrm{T}}\right)=\operatorname{EX}\left[\varepsilon_{\mathrm{T}}(\varphi, \mathrm{z})\right]$ - expected value of random gap height, $\Omega(\varphi, \mathrm{z})$ - lubrication surface.

Putting the derivatives of expectancy values of random lubricant velocity components into expressions (15), we obtain finally the expected values of random friction force components:

$$
\begin{aligned}
& \operatorname{EX}\left(\mathrm{F}_{\mathrm{R} \varphi}\right)=\iint_{\Omega}\left(\frac{\partial \mathrm{EX}(\mathrm{p})}{\partial \varphi}-\mathrm{R} \cdot \mathrm{M}_{\varphi}\right)\left[\operatorname{EX}\left[\varepsilon_{\mathrm{T}}(\varphi, \mathrm{z})\right]-\frac{\int_{0}^{\mathrm{EX}\left(\varepsilon_{\mathrm{T}}\right)} \frac{\mathrm{rdr}}{\operatorname{EX}\left(\varepsilon_{\mathrm{T}}\right)}}{\int_{0}^{\mathrm{EX}\left(\eta_{\mathrm{T}}\right)}} \frac{\mathrm{dr}}{\operatorname{EX}\left(\eta_{\mathrm{T}}\right)}\right] \mathrm{d} \varphi \mathrm{dz}-\omega \mathrm{R}^{2} \iint_{\Omega}\left[\frac{1}{\operatorname{EX}\left(\varepsilon_{\mathrm{T}}\right)} \frac{\mathrm{dr}}{\operatorname{EX}\left(\eta_{\mathrm{T}}\right)}\right] \mathrm{d} \varphi \mathrm{dz},
\end{aligned}
$$

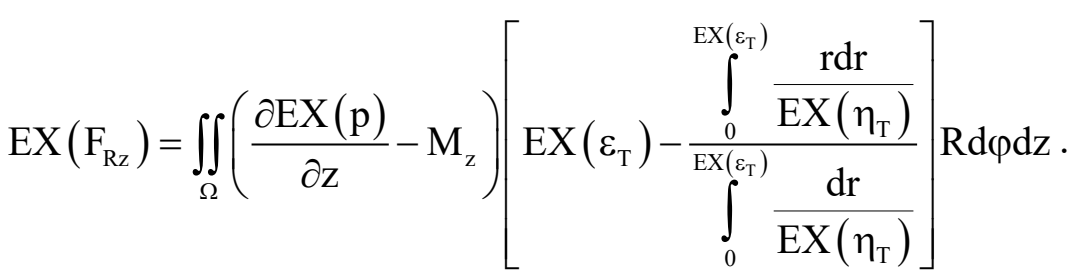

Expected value of the load carrying capacity $\mathrm{C}$ in $[\mathrm{N}]$ situated in opposite side to the load direction has the form:

$$
\operatorname{EX}(C)=\sqrt{\left[\int_{-b}^{b}\left(\int_{0}^{\varphi_{k}} \operatorname{EXp}(\varphi, z) R(\sin \phi) d \varphi\right) d z\right]^{2}+\left[\int_{-b}^{b}\left(\int_{0}^{\varphi_{k}} \operatorname{EXp}(\varphi, z) \operatorname{R}(\cos \varphi) d \varphi\right) d \vartheta\right]^{2}} .
$$


Symbol $\varphi_{\mathrm{k}}$ denotes the end coordinate of the film in circumferential direction and $0 \leq \varphi<2 \pi \theta_{1}$, $0 \leq \theta_{1}<1,-b \leq \mathrm{z} \leq+\mathrm{b}$. Taking into account the Coulomb Law for friction forces, then dimensionless expected friction coefficient $\operatorname{EX}(\mu)$ has the following form:

$$
\operatorname{EX}(\mu)=\frac{\left|\mathbf{e}_{1} \operatorname{EX}\left(F_{\mathrm{R} \phi}\right)+\mathbf{e}_{3} \operatorname{EX}\left(\mathrm{F}_{\mathrm{Rz}}\right)\right|}{\operatorname{EX}(\mathrm{C})},
$$

where $\mathbf{e}_{1}, \mathbf{e}_{3}$ are the unit vectors in circumferential $\varphi$ and longitudinal $\mathrm{z}$ directions.

\section{Upper and lower limits of expectancy tribological parameters}

At first we find the probabilistic density function $\mathrm{f}$ of random correction function $\delta_{1}$ defined in equation (2a) where we have $\operatorname{EX}\left(\delta_{1}\right)=\mathrm{m}$. Equation (3) determines standard deviation $\sigma$. Hence from expressions (2b), (1a) we obtain the following estimation of expected value of gap height:

$$
(1+\mathrm{m}-\sigma) \varepsilon_{\mathrm{T}}(\delta=0) \leq \mathrm{EX}\left(\varepsilon_{\mathrm{T}}\right) \leq(1+\mathrm{m}+\sigma) \varepsilon_{\mathrm{T}}(\delta=0),
$$

where $\varepsilon_{\mathrm{T}}(\delta=0)$ denotes the gap height without random corrections.

The random increments (decrements) of the gap height imply decreases (increases) of random average velocities of lubricant and simultaneously the decreases (increases) of the shear rates during the non-Newtonian lubricant flow, respectively. Hence, we obtain increases (decreases) of the dynamic viscosity of lubricant. Thus follows that the random increments (decrements) of the gap height imply the increases (decreases) of the lubricant viscosity. Therefore valid following inequality:

$$
(1+\mathrm{m}-\sigma) \cdot \eta_{\mathrm{T}}(\delta=0) \leq \operatorname{EX}\left(\eta_{\mathrm{T}}\right) \leq(1+\mathrm{m}+\sigma) \cdot \eta_{\mathrm{T}}(\delta=0) .
$$

Symbol $\eta_{\mathrm{T}}(\delta=0)$ denotes the viscosity for gap height without random corrections.

Expected value of the microbearing load carrying capacity had been obtained from (17) for $\mathrm{C}=\mathrm{pS}$, where $\mathrm{S}=\mathrm{Rd} \varphi \mathrm{dz}$ denotes lubricated surface. By virtue of $\operatorname{EX}(\mathrm{p})$ obtained from (13) and after inequalities (19), (20) we obtain the following estimation of the load carrying capacity:

$$
\frac{\mathrm{R}^{2} \mathrm{~S} \omega \eta_{\mathrm{T}}(\delta=0)}{\varepsilon_{\mathrm{T}}^{2}(\delta=0)} \frac{1+\mathrm{m}-\sigma}{(1+\mathrm{m}+\sigma)^{2}} \leq \mathrm{EX}(\mathrm{C}) \leq \frac{\mathrm{R}^{2} \mathrm{~S} \omega \eta_{\mathrm{T}}(\delta=0)}{\varepsilon_{\mathrm{T}}^{2}(\delta=0)} \frac{1+\mathrm{m}+\sigma}{(1+\mathrm{m}-\sigma)^{2}} .
$$

Taking into account the analytical solutions $(15,16)$ and inequalities $(19,20)$; we obtain following estimation of the expected values of friction forces:

$$
\frac{\mathrm{SR} \omega \eta_{\mathrm{T}}(\delta=0)}{\varepsilon_{\mathrm{T}}(\delta=0)} \frac{1+\mathrm{m}-\sigma}{(1+\mathrm{m}+\sigma)} \leq \operatorname{EX}\left(\mathrm{F}_{\mathrm{R}}\right) \leq \frac{\mathrm{SR} \omega \eta_{\mathrm{T}}(\delta=0)}{\varepsilon_{\mathrm{T}}(\delta=0)} \frac{1+\mathrm{m}+\sigma}{(1+\mathrm{m}-\sigma)} .
$$

Taking into account the analytical solutions $(18)$ and inequalities $(19,20)$ with dependence $\mu=\mathrm{F}_{\mathrm{R}} / \mathrm{C}$, we obtain following estimation of the expectancy values of friction coefficient:

$$
(1+\mathrm{m}-\sigma) \frac{\varepsilon_{\mathrm{T}}(\delta=0)}{\mathrm{R}} \leq \mathrm{EX}\left(\mu=\mathrm{F}_{\mathrm{R}} / \mathrm{C}\right) \leq(1+\mathrm{m}+\sigma) \frac{\varepsilon_{\mathrm{T}}(\delta=0)}{\mathrm{R}} .
$$

\section{Example of probability density function}

The probability density function $\mathrm{f}$ depended on the correction parameter $\delta_{1}$, is always determined in experimental way. By virtue of the many measurement of the microbearing, topography surface after investigations [24-25] follows, that the gap height variations caused by the roughness and its asperities (see Fig. 2) create asymmetrical and symmetrical probability 
functions. In presented considerations is taken into account only the case, where the probability average values of the sum of numerous asymmetrical variations tend finally to the symmetrical function. In symmetrical density function $f$, the probability values of gap height increments assigned to the correction parameter $\delta_{1}$ are symmetrical in relation to the decrements of correction parameter.

For the performed measurements of the many examples of microbearing gap height variations we obtain $1+\mathrm{m}-\sigma=0.5919$ and $1+\mathrm{m}+\sigma=1.4082$. Thus by virtue of inequalities (20-23) the following estimations for expected values of the lubricant viscosity, load carrying capacity, friction forces, friction coefficient have the form:

$$
\begin{gathered}
0.5919 \eta_{\mathrm{T}}(\delta=0) \leq \operatorname{EX}\left(\eta_{\mathrm{T}}\right) \leq 1.4082 \eta_{\mathrm{T}}(\delta=0), \\
0.2984 \frac{\mathrm{R}^{2} \mathrm{~S} \omega \eta_{\mathrm{T}}(\delta=0)}{\varepsilon_{\mathrm{T}}^{2}(\delta=0)} \leq \operatorname{EX}(\mathrm{C}) \leq 4.0194 \frac{\mathrm{R}^{2} \mathrm{~S} \omega \eta_{\mathrm{T}}(\delta=0)}{\varepsilon_{\mathrm{T}}^{2}(\delta=0)}, \\
0.4203 \frac{\mathrm{SR} \omega \eta_{\mathrm{T}}(\delta=0)}{\varepsilon_{\mathrm{T}}(\delta=0)} \leq \operatorname{EX}\left(\mathrm{F}_{\mathrm{R}}\right) \leq 2.3790 \frac{\mathrm{SR} \omega \eta_{\mathrm{T}}(\delta=0)}{\varepsilon_{\mathrm{T}}(\delta=0)}, \\
0.5919 \frac{\varepsilon_{\mathrm{T}}(\delta=0)}{\mathrm{R}} \leq \operatorname{EX}\left(\mu=\frac{\mathrm{F}_{\mathrm{R}}}{\mathrm{C}}\right) \leq 1.4082 \frac{\varepsilon_{\mathrm{T}}(\delta=0)}{\mathrm{R}}
\end{gathered}
$$

\section{Conclusions}

On the ground of performed random analytical solutions and stochastic estimations with elaborated example of symmetrical density function follows:

- the height variations of the investigated microbearing gap attains decreases and increases about $40 \%$ in comparison with gap height without random corrections,

- the expected value of friction forces occurring in investigated microbearing gap between two cooperating surfaces attains decreases from $0.4203 \mathrm{~F}_{\mathrm{R}}(\delta=0)$ and increases to $2.3790 \mathrm{~F}_{\mathrm{R}}(\delta=0)$ in comparison with the friction forces $\mathrm{F}_{\mathrm{R}}(\delta=0)$ without random corrections of gap height,

- the expected value of friction coefficient occurring in investigated microbearing gap attains decreases from $0.5919 \mu(\delta=0)$ and increases to $1.4082 \mu(\delta=0)$ in comparison with the friction coefficient $\mu(\delta=0)$ without random corrections of gap height.

\section{References}

[1] Asada, T., Saito, H., Asaida, Y., Itoh, K., Design of hydrodynamic bearings for high-speed $H D D$, Microsystem Technologies, Vol. 8, Iss. 2-3, pp. 220-226, 2002.

[2] Asada, T. et al, Hydrodynamic bearings and applied technologies, Matsushita Tech., Vol. 46 (1), pp. 54-76, 2000.

[3] Bhushan, B., Handbook of Micro/Nano Tribology, second ed. CRC Press, Boca Raton, London, New York, Washington D.C. 1999.

[4] Bhushan, B., Nanotribology and nano-mechanics of MEMS/NEMS and BioMEMS/BioNEMS materials and devices, Microelectronic Engineering, Vol. 84, pp. 387-412, 2007.

[5] Bhushan, B., Principles and applications of tribology, John Wiley and Sons, New York 1999.

[6] Cwanek, J., The usability of the surface geometry parameters for the evaluation of the artificial hip joint wear, Rzeszów University Press, Rzeszów 2009.

[7] Fisz, M., Probability Theory and Mathematical Statistics, J. Wiley \& Sons, Inc., N.Y. 1963.

[8] Jang, G. H., Lee, S. H., Kim, H. W., Kim, C. S., Dynamic analysis of a HDD spindle system with FDBs due to the bearing width and asymmetric grooves of journal bearing, Microsystem Technologies, Vol. 11, pp. 499-505, 2005. 
[9] Jang, G. H., Park, S. J., Kim, C. S., Han, J. H., Investigation of the electromechanical variables of the spindle motor and the actuator of HDD due to positioning and the free fall, Microsystem Technologies, Vol. 13, pp. 797-809, 2007.

[10] Lee, J., Jang, G., Ha, H., Robust optimal design of the FDBs in a HDD to reduce NRRO and $R R O$, Microsystem Technologies, Vol. 18 (9-10), pp. 1335-1342, 2012.

[11] Oczoś, K., Lubimov, V., Geometrical structure of surface (in Polish), Rzeszów University Publishing House, 2003.

[12] Sharma, S., Hargreaves, D., Scott, W., Journal bearing performance and metrology issues, Journal of Achievements in Materials and Manufacturing Engineering, Vol. 32 (1), pp. 98-103, 2009.

[13] Wierzcholski, K., Miszczak, A., Khudoley, A., The intelligent operation of nano grooved microbearing surfaces in computer HDD, Tribologia, No. 1 (241), pp. 157-166, 2012.

[14] Wierzcholski, K., Miszczak, A., Electro-Magneto-Hydrodynamic Lubrication, Open Physics, Vol. 16 (1), pp. 285-291, 2018.

[15] Wierzcholski, K., Miszczak, A., Khudoley, A., Measurement of non used microbearing occurring in computer HDD Seagate Barakuda, Journal of KONES Powertrain and Transport, Vol. 18, No. 2, pp. 477-482, 2011.

[16] Wierzcholski, K., Miszczak, A., Khudoley, A., Measurement of non used microbearing grooved surfaces for computer ventilator Xilence Case Fan, Journal of KONES Powertrain and Transport, Vol. 18, No. 2, pp. 471-476, 2011.

[17] Wierzcholski, K., Logical network design of microbearing systems. Journal of KONES Powertrain and Transport, Vol. 18, No. 2, pp. 455-462, 2011.

[18] Yuan, C. Q., Peng, Z., Yan, X. P., Zhou, X. C., Surface roughness evaluation in sliding wear process, Wear, Vol. 265, pp. 341-348, 2008.

Manuscript received 25 March 2019; approved for printing 25 June 2019 